\title{
IN VITRO ANTIMICROBIAL ACTIVITY OF COCONUT SHELL LIQUID SMOKE AGAINST CANDIDA ALBICANS AND LACTOBACILLUS ACIDOPHILUS ATTRIBUTING TO ENDODONTIC TREATMENT FAILURE
}

\author{
Isniya Nosartika $^{1 *}$, Nadia Hardini ${ }^{1}$, Tyas Prihatiningsih ${ }^{1}$ \\ ${ }^{1}$ Department of Dentistry, Faculty of Medicine, Diponegoro University, Semarang, Indonesia \\ * Corresponding author, E-mail: nyromah@gmail.com
}

\begin{abstract}
Backgorund : L. acidophilus bacteria and C. albicans fungi are the most common microorganisms isolated from the oral cavity of patients suffering from post-treatment of root canal endodontic infections. Chlorophenol Camphor menthol $(\mathrm{ChM})$ is one of the antimicrobials used for root canal sterilizer but it still has many flaws. Coconut shell liquid smoke (CS-LS) is a natural product that has an antimicrobial activity and non-toxic chemical compounds for humans. Objective: This study aims at determining the minimum inhibitory concentration (MIC) and minimum bactericidal concentration (MBC) of L. acidophilus bacteria and C. Albicans fungi and comparing the antimicrobial activity between CS-LS with commercial root canal sterilization. Method : The MIC and MBC of CS-LS were measured using 10 different concentrations ranging from 10-100\%. MIC was determined by the broth dilution method. All concentration was cultured on each agar media to determine its MBC. The data were analyzed using the comparative test of Kruskall-Wallis with post-hoc Mann-Whitney. Result : MIC and MBC of C. albicans were $10 \%$ of CSLS. Meanwhile, L. acidophilus has the MIC with a 50\% concentration of CSLS and MBC with a $60 \%$ concentration of CS-LS. No significant difference in CS-LS and ChKM was found. Conclusion: CS-LS has a potential for endodontic treatment failure. Further research should be conducted to know other potential uses of CSLS in dentistry.
\end{abstract}

Keywords : L. Acidopilus, C. albican, ChKM, CS-LS

\section{INTRODUCTION}

Pulpoperiapical abnormalities are the result of host response and microbial pathogenic effects. The goal of endodontic treatment by a clinician is to disturb the bacterial ecosystem associated with disease pathogenesis. Endodontic treatment includes primary and secondary endodontic treatments. The microorganisms involved in primary infection are different from secondary infections.

Bacteria isolated from root canals in cases of endodontic failure include gram-positive bacteria, one of them is Lactobacillus acidophilus. Peptidoglycan (PG) is a virulence factor of gram-positive bacteria that can react with the immune system and upregulate proinflammatory and anti-inflammatory cytokines, and facilitate adaptive immune responses through macrophages. Lipoteichoic acid (LTA) is a cell wall component of gram-positive bacteria inducing cell lysis and binding to target cells causing interaction with antibodies and activating complement pathways. ${ }^{1}$

Antimicrobial agents in endodontic treatment are used to eliminate microbes in root canals. Several materials are known and used for both irrigation and root canal sterilization. One of the materials used as a root canal sterilizer is chlorophenol camphor menthol (ChKM) which has a higher antibacterial, antiseptic, and disinfectant potentials compared to other disinfectants made from phenol. According to Dammaschake et al., ChKM was effective in eliminating E. faecalis. The antibacterial mechanism of ChKM is similar to other paraclofenol-based materials containing camphor, disturbing cell membranes through the proteins and membrane lipids bonding. ${ }^{2}$

Other root canal sterilizers that are still used in the endodontic treatment are cresophene and rockles. Cresophene consists of dexamethasone acetate, thymol, paraclorophenol, and racemic champhor. Rockles consist of dexamethasone acetate, phenol, guaiacol. Both of these sterilizers have a strong bactericidal effect. ${ }^{3}$

Intraradicular primary infection is an infection of the root canal which begins with bacterial invasion through the exposed pulp and continued with bacteria colonization. The exposed pulp may occur as a result of caries or trauma involving hard tissue that cause damage 
to the whole tooth structure. Bacteria that have proliferated can lead to acute or chronic conditions depending on the virulence and host defense mechanisms of the host. In this condition, bacteria are mostly anaerobic, containing 10-30 species per root canal. ${ }^{4}$

Microbes that are often found in retreatment case are facultative gram-positive bacteria such as Streptococcus spp., Lactobacillus spp., Actinomyces spp., Propionibacterium spp., coliform bacteria, and C. albicans yeast. ${ }^{5}$

In vivo study showed that root-canal disinfecting agents are highly effective against microbes, even resistant microbes. Worse result of a disinfecting agent in root canal than in vivo result is due to many disturbance factors negatively affecting disinfection outcomes. Haapasalo et al. and Portenier et al. studied the effect of dentine and other substances present in the root canal environment on the antibacterial effect of commonly used intracanal drugs, such as calcium hydroxide, chlorhexidine, and IPI against $E$. faecalis. This study showed that these disinfectants were negatively affected by the various substances tested, calcium hydroxide was very sensitive to the inhibitory effects of various substances present in the root canal. ${ }^{5,6,7}$ A study on the human root canal from Ando and Hoshino found that the composition of the microflora invaded the deepest layer of root canal dentin $(0.5-2 \mathrm{~mm}$ from the root surface wall) consisted of more bacteria found after anaerobic incubation than after aerobic incubation with $30 \% \mathrm{CO}_{2}$. Of the 256 bacteria found, $80 \%$ were anaerobic species. The bacteria found include Lactobacillus spp. (30\%), Streptococcus spp. (13\%) followed by Propionibacterium sp. (9\%). ${ }^{8}$

Microorganisms are the main cause of the failure of endodontic treatment, especially the presence of polymicrobial interactions. Fungi play a crucial role in root canal infections and reinfection. The genus Candida, in particular Candida albicans, are the most common fungi found in the root canals of teeth with primary endodontic infections. The ability of $C$. albicans to grow well at $37{ }^{\circ} \mathrm{C}$ allows it to grow in human and animal cells. Even though it has a changeable form, the form of yeast and filaments play a very important role in the process of infection in the host body. ${ }^{9}$

ChKM sterilization agent is still used in root canal treatment practices up until now. Although in some literature, it is stated that this material has a low biocompatibility, such as the possible toxicity caused by its 4-chlorophenol and chlorophenol contents. Besides, the price is expensive. For that reason, several studies have been carried out to study alternative materials, such as natural products or herbs, which have the potential as root canal sterilization agents. One of the natural products having the potential of antibacterial activity is coconut shell liquid smoke (CS-LS). The chemical components of liquid smoke are bacteriostatic and bactericidal. ${ }^{10}$

Liquid smoke is a compound that evaporates simultaneously from the heat reactor through pyrolysis technique (heat decomposition) and condenses in the cooling system. ${ }^{11}$ Chemical components contained in CS-LS are phenols which have the highest proportion, phenol derivatives such as 2methylphenol and 3-methylphenol, other components that are ketones, guaiakol, alkyl aryl ether, and acids acetate. ${ }^{12}$ Phenol and acetic acid act as antimicrobials. Liquid smoke can inhibit the growth of the bacteria Pseudomonas fluoresense, Bacillus subtilis, Eschercia coli and Staphylococcus aureus..$^{10}$

Liquid smoke is indirectly the result of combustion, but with the evaporation method in the manufacturing process, polycyclyc aromatic hydrocarbons (PAH) including benzo(a)pyrene are not found in liquid smoke. According to Budijanto et al., $\mathrm{LD}_{50}$ of CS-LS was more than $15,000 \mathrm{mg} / \mathrm{kg}$ weight of the tested animal. This implied that CS-LS was a non-toxic and safe material for food products. ${ }^{12}$

Liquid smoke contains antibacterial and antioxidant compounds making its use diverse including the food industry as a preservative, health industry, plant fertilizers, bioinsecticides, pesticides, disinfectants, herbicides, and so on. Analysis of the chemical components of liquid smoke has been conducted by several researchers and it is known that the constituent components include phenol, 2-methoxy phenol, 1,2-benzenediol, 4 methyl catechols, 2,6- 
dimethoxy phenol, and 3 methyl-1,2benzenediol.21 Another study conducted by Zuraida et al. stated that the constituent components of liquid smoke include phenol and its derivatives are phenol, 2-methylphenol, 3methylphenol, 2,6-dimethylphenol, 2,4dimethylphenol and 3-ethylphenol. While carbonyl and acids include 1-Cyclohexene-1carboxaldehyde, 2,3-dihydroxy-benzoic acid, 3methoxybenzoic acid methyl ester, and 4hydroxy-benzoic acid methyl ester. ${ }^{13}$

On the other hand, a medicament is used to improve the prognosis of endodontic treatment. The medicament is expected to penetrate into the dentinal tubule and kill the bacteria. A variety of medicaments are used for complete root canal disinfection. ${ }^{14}$ The goals of intracanal medicament administration are to reduce periradicular inflammation, thereby reduce pain between visits, reduce the number/ kill and prevent bacterial regrowth, help eliminate periapical exudate if present, prevent or retain root resorption if present, and prevent re-infection of the root canal system as a chemical and physical barrier when the temporary restoration leaks. ${ }^{15}$

Thus, bacterial resistance that causes endodontic treatment failure is still a major obstacle in the endodontic field, besides that the existing root canal sterilization materials still have many flaws. Thus, the researchers wanted to examine the bacterial effect of coconut shell liquid smoke (CS-LS) on the growth of bacteria causing endodontic treatment failure in an in vitro study.

The aims of this research are to prove that CS-LS has an antimicrobial effect on microorganisms causing endodontic treatment failure, to know the minimum inhibition level of CS-LS against the microorganisms causing endodontic treatment failure, and to determine the antibacterial effectivity of CS-LS against microorganisms that cause endodontic treatment failure compared to rockles, cresophen and ChKM.

\section{METHODS}

This study was conducted from September to October 2018 at the microbiology laboratory of the Faculty of Medicine,
Diponegoro University. This was an experimental in vitro study with a post-test only control group design. This study consisted of 40 samples divided into 4 groups, determining the minimum inhibitory concentration (MIC) and minimum bactericidal concentration (MBC) of L. acidophilus bacteria and C. Albicans fungi and comparing the antimicrobial activity between CS-LS with commercial root canal sterilization. The MIC and MBC of CS-LS were measured using 10 different concentrations ranging from $10-100 \%$.

Candida albicans ATCC 10231 and $L$. acidophilus ATCC 4356 were used in this study. The culture of Candida albicans ATCC 1023 was done on brain heart infusion (BHI) broth. Meanwhile, the culture of $L$. acidophilus ATCC 4356 was done in deMan Rogosa and sharpe broth (MRS-B). One ose of the colony was cultured in 0.5 of each media and incubated for 24 hours at $37^{\circ} \mathrm{C}$. The suspension was homogenized using vortex and diluted in distilled water using Mc Farland standard 0,5 $\left(1 \times 10^{8} \mathrm{CFU} / \mathrm{ml}\right)$.

MIC and MBC of CS-LS against Candida albicans and Lactobacillus acidophillus were done with concentrations of $10 \%, 20 \%, 30 \%, 40 \%, 50 \%, 60 \%, 70 \%, 80 \%$, $90 \%$ and $100 \%$ of CS-LS. Rockles, cresophene dan ChKM were used as a comparison of antibacterial activity of CS-LS.

MIC was done by broth dilution method. CS-LS with concentrations ranging from $10-100 \%$ was added into the tube containing a $0.5 \mathrm{ml}$ of suspension from Candida albicans ATCC 10231 and L. acidophilus ATCC 4356. A distilled water is used in the tube as a negative control. The tube is vortexed and incubated for 24 hours at $37^{\circ} \mathrm{C}$. MIC was determined by the smallest concentration of CSLS with lower turbidity.

The number of colonies in each tube of broth dilution was calculated by colony counter. A $0.1 \mathrm{ml}$ of suspension was cultured in each media by using the spread plate method. The culture of Candida albicans ATCC 1023 for colony counter was done on Sobouraund Dextrose Agar (SDA). Meanwhile, the culture of L. acidophilus ATCC 4356 was done in deMan Rogosa and sharpe broth (MRS-B). The media 
was incubated in $37^{\circ} \mathrm{C}$ for 48 hours. The number of colony was presented as $\mathrm{CFU} / \mathrm{ml}$. MBC was determined by the smallest concentration of CSLS showing no growth of culture in plate media. Statistical analysis was done by comparative analysis of Kruskall-Wallis with post-hoc MannWhitney. A value of $p<0.05$ was considered significant.

\section{RESULT}

Table 1. MIC of CS-LS against L. Acidophilus

\begin{tabular}{llllll}
\multicolumn{7}{c}{ ATCC 4356} \\
\hline & I & II & III & IV & V \\
\hline $100 \%$ & - & - & - & - & -
\end{tabular}

\section{CS-LS}

$90 \%$ CS-

LS

$80 \%$ CS-

LS

$70 \%$ CS-

LS

$60 \%$ CS-

LS

$50 \%$ CS-

LS

$40 \% \mathrm{CS}_{-}+\quad+\quad+\quad+$

LS

$30 \%$ CS-

LS

$20 \%$ CS- $+\quad+\quad+\quad+$

LS

$10 \%$ CS-

LS

Control $+\quad+\quad+\quad+\quad+\quad+\quad+$

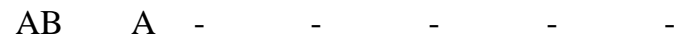

(Cresotin)

$\mathrm{AB} \quad \mathrm{B}$

(CHKM)

Note : + indicated turbid broth media, - indicated clear brooth media

A $40 \%$ of CS-LS showed a turbid broth media of L. Acidophilus ATCC 4356. This indicated that a $40 \%$ of CS-LS can not inhibit the growth of L. Acidophilus ATCC 4356. Meanwhile, the smallest concentration of CS-LS that can inhibit L. Acidophilus ATCC 4356 growth was $50 \%$. A $50 \%$ of CS-LS is significantly different from $40 \%$ of CS-LS $(\mathrm{p}=0.014)$ and positive control $(\mathrm{p}=0.003)$. No significant difference between $40 \%$ of CS-LS and Control negative $(\mathrm{p}=1.000)$. Thus, $50 \%$ concentration was a MIC for CS-LS against $L$. Acidophilus ATCC 4356.

Tabel 2. MBC of CS-LS against L. Acidophylus ATCC 4356

\begin{tabular}{|c|c|c|c|c|c|}
\hline & $\mathbf{I}$ & II & III & IV & $\mathbf{V}$ \\
\hline $100 \%$ & - & - & - & - & - \\
\hline CS-LS & & & & & \\
\hline $90 \%$ CS-LS & - & - & - & - & - \\
\hline $80 \%$ CS-LS & - & - & - & - & - \\
\hline $70 \%$ CS-LS & - & - & - & - & - \\
\hline $60 \%$ CS-LS & - & - & - & - & - \\
\hline $50 \%$ CS-LS & + & + & + & + & + \\
\hline $40 \%$ CS-LS & + & + & + & + & + \\
\hline $30 \%$ CS-LS & + & + & + & + & + \\
\hline $20 \%$ CS-LS & + & + & + & + & + \\
\hline $10 \%$ CS-LS & + & + & + & + & + \\
\hline Control + & + & + & + & + & + \\
\hline $\begin{array}{l}\mathrm{AB} \\
\text { (Cresotin) }\end{array}$ & - & - & - & - & - \\
\hline $\begin{array}{ll}\mathrm{AB} & \mathrm{B} \\
(\mathrm{CHKM})\end{array}$ & - & - & - & - & - \\
\hline
\end{tabular}

Note : + indicated growth of bacteria in media, indicated no growth of bacteria inmedia

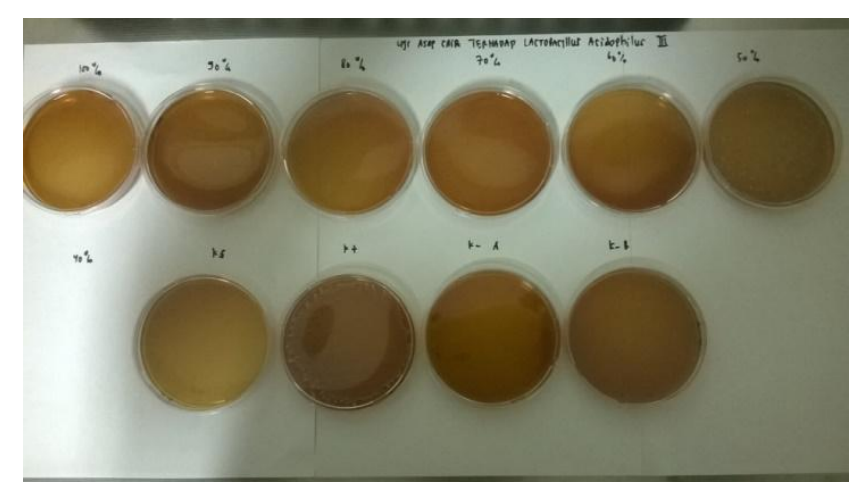

Fig. 1 Growth of Cultured L. Acidophylus ATCC 4356 with concentration ranging from $10-100 \%$

The bacteria were then cultured on agar media. A $60 \%$ of CS-LS showed no growth of $L$. Acidophilus ATCC 4356. Thus, 60\% concentration was a MIC of CS-LS against $L$. Acidophilus ATCC 4356.

On the other hand, $10 \%$ of CS-LS is capable to inhibit the growth of Candida albicans ATCC 1023 in broth media and cultured agar media. Thus, the MIC and MBC of CS-LS against Candida albicans ATCC 1023 in this research was $10 \%$. 
Table 3. MIC of CS-LS against Candida albicans ATCC 1023

\begin{tabular}{llllll}
\hline & I & II & III & IV & V \\
\hline $100 \%$ & - & - & - & - & - \\
CS-LS & & & & & \\
$90 \%$ CS-LS & - & - & - & - & - \\
$80 \%$ CS-LS & - & - & - & - & - \\
$70 \%$ CS-LS & - & - & - & - & - \\
$60 \%$ CS-LS & - & - & - & - & - \\
$50 \%$ CS-LS & - & - & - & - & - \\
$40 \%$ CS-LS & - & - & - & - & - \\
$30 \%$ CS-LS & - & - & - & - & - \\
$20 \%$ CS-LS & - & - & - & - & - \\
$10 \%$ CS-LS & - & - & - & - & - \\
Control + & + & + & + & + & + \\
AB A & - & - & - & - & - \\
(Cresotin) & & & - & - & - \\
AB B & - & - & - & & \\
$($ CHKM) & & & &
\end{tabular}

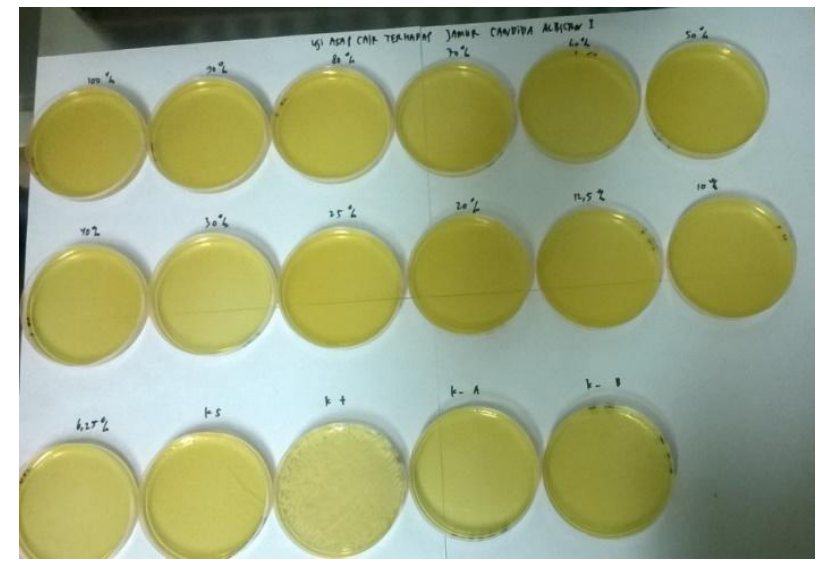

Fig. 2 Growth of Cultured Candida albicans ATCC 1023 with concentration ranging from $10-100 \%$

\section{DISCUSSION}

CS-LS is obtained from the pyrolysis process and smoke condensation of the coconut shell burning process. CS-LS is known to have a high polyphenol content. Polyphenols are not only well-known as good antioxidants but also a good antimicrobial agent. The phenol content in liquid smoke acts as an antifungal by inhibiting fungal nucleic synthesis. This phenol group can also disrupt the stability of the cell membrane and the metabolism of fungal cells so that it disturbs fluid exchange within the cell. Moreover, phenols inhibit the growth of microorganisms by disrupting cell wall permeability and resulting in cell wall damage. According to study on the effect of liquid smoke concentration as a disinfectant solution on decreasing Candida albicans, found that the phenol content in liquid smoke with a concentration of $2 \%$ has an effect on decreasing the growth of $C$. albicans. This research was found that a $10 \%$ of CS-LS could inhibit the growth of Candida albicans. ${ }^{9}$

Candida Albicans is not only found in denture user but also a patient with root canal treatment. On patient with root canal treatment, Candida albicans is difficult to be removed. Thus, CS-LS has a potential to remove Candida Albicans in patients with root canal treatment. ${ }^{9}$

Other bacteria may also contribute to be complicating factors and endodontic failure. This study observed the effect of CS-LS against Lactobacillus acidophilus that are bacteria contributing to endodontic failure. The result suggests that CS-LS has the potential to inhibit the growth of Lactobacillus acidophilus with a concentration of $50 \%$. Thus, CS-LS has the potential to remove Lactobacillus acidophilus in a patient with root canal treatment.

The use of CS-LS for endodontic treatment is practical and affordable. Moreover, daily use of CS-LS is by adding it to food. For that reason, CS-LS is safe and less toxic for human.

\section{CONCLUSION AND SUGGESTION}

A $10 \%$ of CS-LS inhibits the growth of Candida albicans. Meanwhile, Lactobacillus acidophilus growth is inhibited with $50 \%$ concentration of CS-LS. There is no signifacant difference between CS-LS and ChKM. Thus, CS-LS has a potential antibacterial activity for endontic treatment failure. Further research should be conducted to determine the spectrum of antibacterial activity of CS-LS and potential of CS-LS as another medicine in root canal treatment, for example as an irrigation solution in clinical setting.

\section{REFRENCES}

1. Narayanan L L, Vaishnavi C. Endodontic microbiology. $J$ Conserv Dent. 2010;13:233-9

2. Dammaschake $t$, Jung $N$, Hark $I$, dan Schafer E. The effect of different root canal medicaments on the elimination 
of Enterococcus faecalis ex vivo. Eur $J$ Dent. 2013. 7(4): 442-448.

3. Cristea A.D, Preoteasa C.T, Popa M, et.al. In Vitro Testing of Susceptibility to Endodontic Irrigants and Disinfectants of Bacterial Strains Isolated from Chronic Apical Periodontitis. Romanian Biotechnological Letters. $2016 . \quad 21(1)$ : 11217-11223.

4. Siguera, dkk., J Dent Res. 2009 Nov;88(11):969-81

5. Waltimo TM, Sen BH, Meurman JH, Orstavik D, Haapasalo MP. Yeasts in apical periodontitis. Crit Rev Oral Biol Med. 2003.14: 128-137.

6. Portenier I, Haapasalo H, Rye A, Waltimo T, Orstavik D, Haapasalo M. Inactivation of root canal medicaments by dentine, hydroxylapatite and bovine serum albumin. Int Endod J; 2001. 34: 184-188.

7. Haapasalo, H., Udnaes, T. 2003. Endal, U. Endodontic Topics; 6, 29-56

8. Ando N, Hoshino E. Predominant obligate anaerobes invading the deep layers of root canal dentin. Int Endod J. 1990. 23: 20-27

9. Andrada Tonea, Mandra Badea, Liviu Oana, Sorina Sava, Dan Vodnar. Antibacterial And Antifungal Activity Of Endodontic Intracanal Medications, Clujul Medical. 2017. Vol.90, No.3, 2017: 344-347.

10. Ayudiarti D.L, dan Sari R.N. Asap Cair dan aplikasinya Pada Produk Perikanan. Squalen. 2010. 5 (3): 101-108.

11. Simon R, Calle B, Palme S, Meler D, dan Anklam, E. Composition and analysis of liquid smoke flavouring primary products. J. Food Sci. 2005. 28: 871-882.

12. Budijanto S, Hasbullah R, Prabawati S, Setyadit, Sukarno, dan Zeraida I. Identifikasi Dan Uji Keamanan Asap Cair Tempurung Kelapa Untuk Produk Pangan. J Pascapanen. 2008. 5 (1): 32-40.

13. Zuraida I, Hasbullah R, Budijanto S. Aktivitas Antibakteri Asap Cair dan Daya Awetnya terhadap Bakso Ikan. J Ilmu Pertan Indones; 2009. 14:41-49.

14. Walton RE, Riviera ME, Torabinejad TM. Walton RE, Riviera ME, Torabinejad TM. Principles and Practice of Endodontic. 2002. Philadelphia: WB Saunder.
15. Mattulada I.K., Pemilihan medikamen intrakanal antar kunjungan yang rasional, Dentofasial, 2010, Vol.9, No.1, April 2010:63-68. 